\title{
Comparative Adsorption Of Dyes Unto Activated Carbon Prepared From Maize Stems And Sugar Cane Stems.
}

\author{
Dada, A.O ${ }^{1 *}$, Inyinbor, A. A ${ }^{2}$, Oluyori, A.P ${ }^{3}$ \\ ${ }^{1,2,3}$ Department of Chemistry, Landmark University, P.M.B. 1001, Omu-Aran, Kwara State, Nigeria. \\ *Corresponding author's e-mail: dada.oluwasogo@landmarkuniversity.edu.ng
}

\begin{abstract}
Comparative adsorption of dyes (bromophenol blue and methyl orange solution) was performed using activated carbon prepared from maize stem and sugarcane stem as low cost agricultural waste adsorbents. The two adsorbents were chemically activated using orthophosphoric acid, potassium hydroxide and zinc chloride. The ash content, percentage fixed carbon and effect of particle sizes were determined. The adsorption capacity of each sample was determined by decolourization of bromophenol blue solution. Three particle sizes $(0.5-0.3 \mu \mathrm{m}, 0.3-0.125 \mu \mathrm{m}$, and $0.125-0.112 \mu \mathrm{m})$ were studied out of which $0.125-0.112 \mu \mathrm{m}$ has the highest quantity of solute adsorbed and this particle size was chosen for the adsorption studies. Of the six activated carbon samples prepared, activated carbon produced from maize stem using orthophosphoric acid, PMA, and activated carbon produced from sugar cane stem using orthophosphoric acid, PSA, have the highest quantity of solute adsorbed, $2.67 \mathrm{mg} / \mathrm{l}$ and $2.66 \mathrm{mg} / \mathrm{l}$ respectively and these compete comparatively with the commercial activated carbon $(C A C)$ with $2.76 \mathrm{mg} / \mathrm{l}$. Their adsorption capacity is due to the highest percentage fixed carbon they both possess from the list of activated carbon prepared. The percentage fixed carbon of PMA and PSA were $84.88 \%$ and $84.80 \%$ respectively. The ability of these activated carbon samples to decolourise dye as compared with commercial activated carbon, CAC, and their low cost make them recommendable for treatment of dye from industrial effluent
\end{abstract}

Keywords: Activated carbon, adsorption, chemical activation, dye.

\section{INTRODUCTION}

The release of inorganic and organic contaminants into our environment is still large and it is increasing in certain areas of the world. The pollution of water resources due to the disposal of contaminants is an increasing worldwide concern for the last few decades. One of the most common water pollutants is colour. They are release into the water by the discharge of dyes from paper and pulp industries, textile industries, tanning industries and many other industries [1]. Colour in the water affects the nature of water, inhibit sunlight penetration and reduce photosynthetic action. Some of the dyes cause rapid depletion of dissolved oxygen affecting aquatic life adversely. Some of the dyes are toxic and carcinogenic. Thus, uses of dye contaminated water without any treatment may cause adverse effect on human health, domestic animals, wildlife and on the environment. So it is necessary to treat or remove colour from the industrial effluent before discharge [2]. A wide range of various treatment methods (namely, ion exchange, biodegradation, oxidation, solvent extraction and adsorption) have been reported to be used for removal of organic pollutants from industrial effluents [3]. However, adsorption has been universally accepted as one of the most effective pollutant removal process, with low cost, ease in handling, low consumption of reagents, as well as scope for recovery of value added components through desorption and regeneration of adsorbent [4,5]. The tremendous application of activated carbon in various areas of our society has created the need to search for cheap sources for its production. Activated carbon has been useful for quality industrial products, pollution control and purification of water [6]. The objective of this work is to prepare activated carbon from maize stem and sugar cane stem using Orthophosphoric acid $\left(\mathrm{H}_{3} \mathrm{PO}_{4}\right)$, Sodium hydroxide $(\mathrm{NaOH})$, and Zinc Chloride $\left(\mathrm{ZnCl}_{2}\right)$ as the activating chemicals and compare their adsorption capacity with the commercial activated carbon (CAC) by the removal of dyes like Bromophenol blue and Methyl orange.

\subsection{Collection and Preparation of Adsorbents}

\section{Materials And Methods}

All the chemicals used were of analytical grade. Maize stems and sugar cane stems were collected from Alagbede farm in Osun State. The samples were sun dried and grounded into pieces in order to enhance carbonization, purification, chemical activation using the methods reported by Adekola and Adegoke [7].

$100 \mathrm{~g}$ of Maize stems and sugar cane stems was carbonized in a specially constructed chamber, after cooling; the charred products were grounded to workable sizes with the use of mortar and pestle. The samples were screened to obtain samples of different size ranges with the use of sieve into $(0.112-0.125) \mu \mathrm{m},(0.125-0.3) \mu \mathrm{m}$, and $(0.3-0.5) \mu \mathrm{m}$. The charred products were purified by placing each charred sample in $0.5 \mathrm{M} \mathrm{HCl}$ in $500 \mathrm{~cm}^{3}$ 
Comparative Adsorption Of Dyes Unto Activated Carbon Prepared From Maize Stems And Sugar

beaker. The mixture was gently stirred and heated until evolution of gas stopped and the mixture formed a paste. The content was filtered and carbon residue was rinsed with de-ionized water until it was neutral to litmus paper. Chemical activation was done using different chemical reagents like $\mathrm{H}_{3} \mathrm{PO}_{4}, \mathrm{KOH}, \mathrm{ZnCl}_{2}$. 25.0g sample of the purified carbon was put into a beaker containing $500 \mathrm{~cm}^{3}$ of $1.0 \mathrm{M} \mathrm{H}_{3} \mathrm{PO}_{4}$. The content was thoroughly mixed and heated until it formed a paste. This was transferred into crucible and placed in a muffle furnace fixed at $500^{\circ} \mathrm{C}$ for 2 hours. The activated sample was allowed to cool to room temperature after which it was washed with de-ionized water until the $\mathrm{pH}$ became neutral, the sample was then dried in an oven at about $80^{\circ} \mathrm{C}-100^{\circ} \mathrm{C}$. The same procedure was repeated using $1.0 \mathrm{M} \mathrm{KOH}$ and saturated solution of $\mathrm{ZnCl}_{2}$ [8].

\subsection{Adsorbate}

Bromophenol Blue: The chemical name is 3', 3", 5',5"-tetrabromophenolsulphonephthalein having the formula weight of $691.97 \mathrm{~g} / \mathrm{mol}$. The transition interval is between $\mathrm{pH}$ of 3.0 (yellow) to $\mathrm{pH}$ of 4.6 (blue). Bromophenol blue was prepared from $0.1 \mathrm{~g}$ of its salt which was dissolved in $50 \mathrm{~cm}^{3}$ of Alcohol and made up to 250 $\mathrm{cm}^{3}$ Methyl Orange: 4-(4-(dimethylamino)phenyl benzene sulphonic acid, sodium salt). Its molecular fomular is $\left(\mathrm{CH}_{3}\right)_{2} \mathrm{NC}_{6} \mathrm{H}_{4} \mathrm{~N}=\mathrm{C}_{6} \mathrm{H}_{4} \mathrm{SO}_{3} \mathrm{Na}$ with the formular weight of $327.34 \mathrm{~g} / \mathrm{mol}$ having the transition interval of $\mathrm{pH} 3.2$ (red) to $\mathrm{pH} 4.4$ (yellow). It was prepared by dissolving $1.0 \mathrm{~g}$ in $1000 \mathrm{~cm}^{3}$ of $\mathrm{H}_{2} 0$ [9].

\subsection{Analyses of the Activated Carbon Samples}

The yield of carbonized product was determined from raw materials by weighing $100 \mathrm{~g}$ of each of the raw materials and carbonized separately. The carbonized product was cooled to room temperature and weighed again. The process was repeated twice.

A sh content and percentage fixed carbon were determined on each sample of the activated carbon. From the previously dried sample of the activated carbon, the carbon content was determined by igniting a carefully weighed $2.0 \mathrm{~g}$ sample of activated carbon in a hot bunsen burner flame and cooled on a desiccator. The crucible containing the ignited carbon was placed in a muffle furnace at $900^{\circ} \mathrm{C}$ for three hours. After heating, the crucible was allowed to cool to room temperature. The cycle of heating in the furnace, cooling and weighing was repeated three times for each samples. The percentage ash content was first determined and the percentage fixed carbon was deduced from it $[7,8]$. From the weight loss, the percentage ash content was calculated. The percentage fixed carbon was also calculated [10].

The effect of particle sizes on activated carbon's adsorption ability was done using different particle sizes ranging from $(0.112-0.125) \mu \mathrm{m},(0.125-0.3) \mu \mathrm{m}$, and $(0.3-0.5) \mu \mathrm{m}$. Sample activated with orthophosphoric acid were chosen for this determination because it has the highest percentage fixed carbon. $0.1 \mathrm{~g}$ of each of these ranges of particle sizes were weighed and put in conical flask. The flask containing $100 \mathrm{~cm}^{3}$ of bromophenol blue solution of $20 \mathrm{mg} / \mathrm{l}$ was covered with rubber stoppers. The mixture was shaken vigorously and continuously on mechanical shaker for three hour. The mixture was then filtered and the absorbance of the filtrate measured at the predetermined wavelength for bromophenol blue using UV-Vis spectrophotometer. Absorbance and Concentration were determined from the calibration graph. The same procedure was followed for the remaining samples of the activated carbon treated with solution of $1 \mathrm{M} \mathrm{H}_{3} \mathrm{PO}_{4}$ [8]. Adsorption of bromophenol blue and methyl orange on activated carbon was carried out. The samples of activated carbon with particle size $(0.112-0.125) \mu \mathrm{m}$ weighing $0.1 \mathrm{~g}$ was measured in each case and was added to $100 \mathrm{~cm}^{3}$ of solution containing $20 \mathrm{mg} / \mathrm{l}$ and $30 \mathrm{mg} / \mathrm{l}$ concentrations of bromophenol blue and methyl orange which were chosen for the determination respectively. The mixture and rubber stopper was shaken vigorously and continuously on a shaker for about three hour. The filtrate after adsorption was measured at the predetermined wavelength of $625 \mathrm{~nm}$ and $490 \mathrm{~nm}$ for Bromophenol blue and Methylorange solutions at $10 \mathrm{~nm}$ and $5 \mathrm{~nm}$ intervals respectively using UV-Vis spectrophotometer. The residual concentration of the filtrate was then determined. The extent of adsorption and the amount of substance adsorbed were gotten and this was repeated for the remaining samples of activated carbon [8].

\section{Results And Discussion}

Percentage Yield of the Carbonized Product

Six different activated carbons were prepared from maize and sugarcane stems using $\mathrm{H}_{3} \mathrm{PO}_{4}, \mathrm{ZnCl}_{2}$ and $\mathrm{KOH}$ as activating agents and they were identified as follows; $\mathrm{H}_{3} \mathrm{PO}_{4}$ activated maize stem carbon (PMA), $\mathrm{ZnCl}_{2}$ activated maize stem carbon (ZMA), $\mathrm{KOH}$ activated maize stem carbon (KMA), $\mathrm{H}_{3} \mathrm{PO}_{4}$ activated sugarcane stem carbon (PSA), $\mathrm{ZnCl}_{2}$ activated sugarcane stem carbon (ZSA), $\mathrm{KOH}$ activated sugarcane stem carbon (KSA). Commercial activated charcoal (CAC) was used as control. The percentage yield of carbonized product is given in table 1 below: 
Comparative Adsorption Of Dyes Unto Activated Carbon Prepared From Maize Stems And Sugar

Table 1: The percentage yield of Carbonized product

\begin{tabular}{|l|l|l|l|l|}
\hline Raw Material & $\begin{array}{l}\text { Weight before Carbonization } \\
(\mathrm{g})\end{array}$ & $\begin{array}{l}\text { Weight after } \\
\text { Carbonization }(\mathrm{g})\end{array}$ & Percentage Yield (\%) & Average (\%) \\
\hline Maize stem & 100 & 24.80 & 24.80 & 25.80 \\
& 100 & 26.80 & 26.80 & \\
Sugar cane stem & 100 & 23.66 & 23.66 & 23.73 \\
& 100 & 23.80 & 23.80 & 2 \\
\hline
\end{tabular}

\subsection{SPECTRA AND STANDARD CALIBRATION GRAPHS FOR THE BROMOPHENOL BLUE} AND METHYL ORANGE SOLUTIONS

The spectra of bromophenol blue and methyl orange solutions are shown in fig 1 and 2 respectively and the wavelength corresponding to the maximum absorbance for these dye solutions was found to be $615 \mathrm{~nm}$ and $490 \mathrm{~nm}$ for bromophenol blue and methyl orange respectively. The wavelength for bromophenol blue and methyl orange nearly correspond to the wavelength of methylene blue and methyl red in the work done reported in the literature[6,8]. In the research, carried out by odebunmi and okeola, 2001, maximum wavelength $\left(\lambda_{\max }\right)$ for methylene blue was found to be $630 \mathrm{~nm}$ and this is nearly the same with that of bromophenol blue at $625 \mathrm{~nm}$.

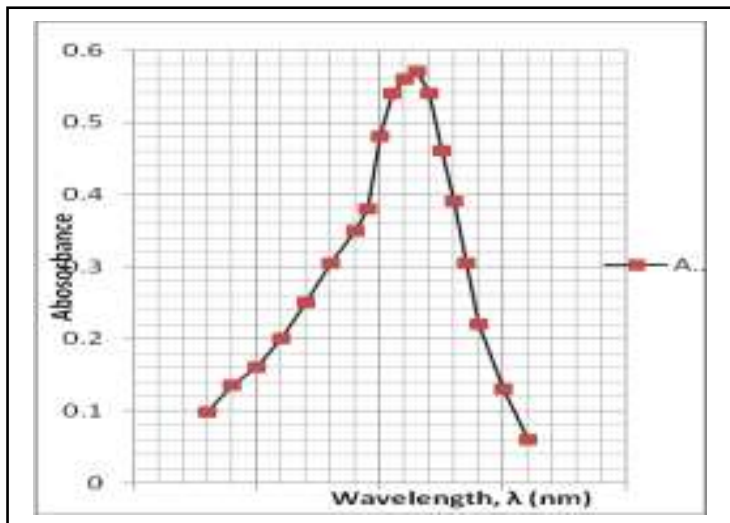

Fig 1: Spectrum of Bromophenol blue solution

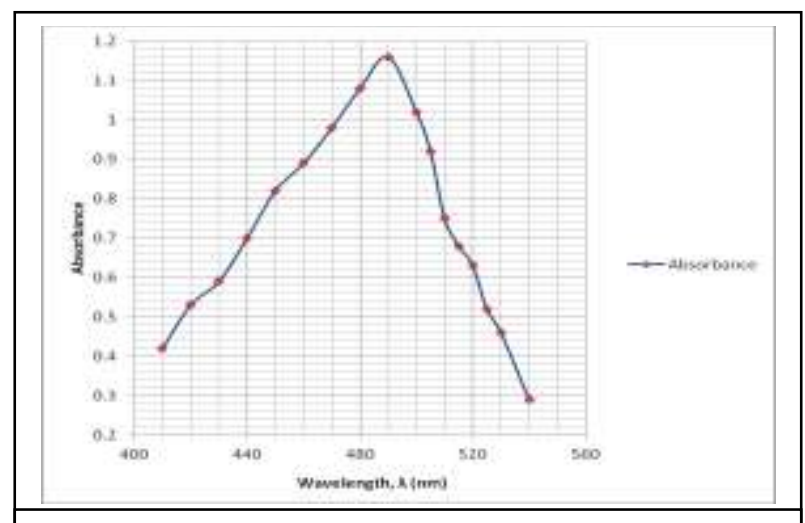

Fig 2: Spectrum Methylorange solution

\subsection{THE STANDARD CALIBRATION GRAPH}

The standard calibration graph for Bromophenol blue and Methyl orange respectively were presented in fig. 3 and 4.

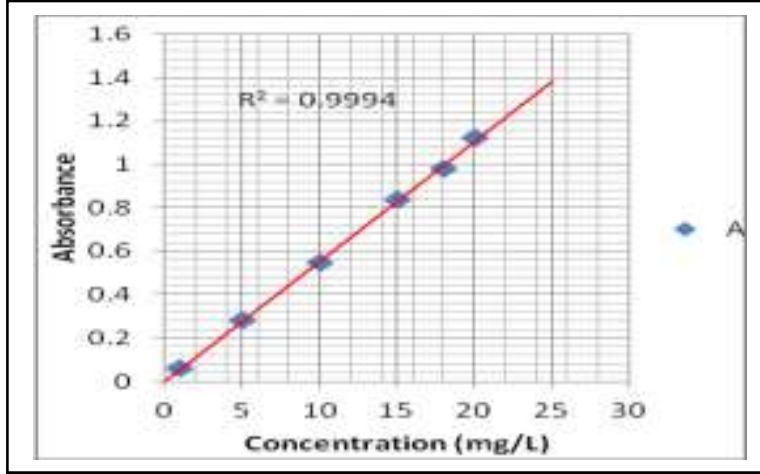

Fig 3: Standard calibration graph for Bromophenol blue

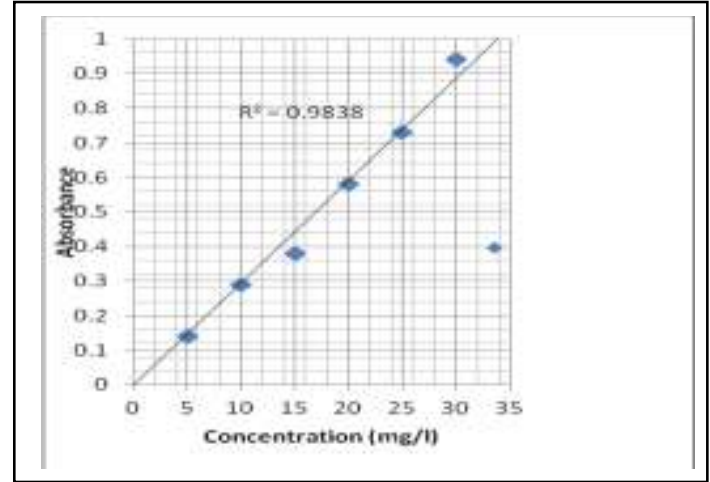

Fig 4: Standard calibration graph for Methylorange

\subsection{EFFECT OF THE PARTICLE SIZE ON THE ADSORPTION CAPACITY OF ACTIVATED CARBON}

Different particle sizes were used to determine the adsorption capacity of activated carbon. The samples of activated carbon activated with orthophosphoric acid were selected for this determination. More so, Bromophenol blue solution was chosen to carry out this determination and the result was presented in form of bar charts. The particle sizes used for this adsorption are $(0.112-0.125) \mu \mathrm{m},(0.125-0.30) \mu \mathrm{m}$ and $(0.3-0.5) \mu \mathrm{m}$. The results are given in table 2 and the pictorial representation is shown on fig 5. From the result, it was observed that the higher the surface area, the higher the quantity of solute adsorbed. This observation correlates with that of Duff and Ross[11] in a related work on the effect of adsorbent particle sizes on the adsorption capacity of activated carbon. This indicates that adsorption capacity of the activated carbon decreases with 
Comparative Adsorption Of Dyes Unto Activated Carbon Prepared From Maize Stems And Sugar increase in the particle sizes as well as increase in the surface area as follows $(0.112-0.125) \mu \mathrm{m}>(0.125-$ $0.3) \mu \mathrm{m}>(0.3-0.5) \mu \mathrm{m}$.

Table 2: The Effect of the Particle Size on the Ability of Activated Carbon to Decolourise Bromophenol Blue Solution

\begin{tabular}{|l|l|l|l|}
\hline $\begin{array}{c}\text { Particle sizes of samples of } \\
\text { activated carbon } \\
(\mu \mathrm{m})\end{array}$ & $\begin{array}{c}\text { Absorbance of } \\
\text { decolourized solution } \\
( \pm 0.001)\end{array}$ & $\begin{array}{c}\text { Concentration of } \\
\text { decolourized solution } \\
( \pm 0.01 \mathrm{mg} / \mathrm{l})\end{array}$ & $\begin{array}{c}\text { Quantity of } \\
\text { solute adsorbed } \\
( \pm 0.1 \mathrm{mg})\end{array}$ \\
\hline PMA & 0.396 & 7.01 & 1.30 \\
$0.5-0.3$ & 0.191 & 3.04 & 1.70 \\
$0.3-0.125$ & 0.148 & 2.04 & 1.80 \\
$0.125-0.112$ & & & \\
\hline PSA & 0.464 & 8.04 & 1.20 \\
$0.5-0.3$ & 0.242 & 4.04 & 1.60 \\
$0.3-0.125$ & 0.158 & 2.08 & 1.79 \\
$0.125-0.112$ & & & \\
\hline
\end{tabular}

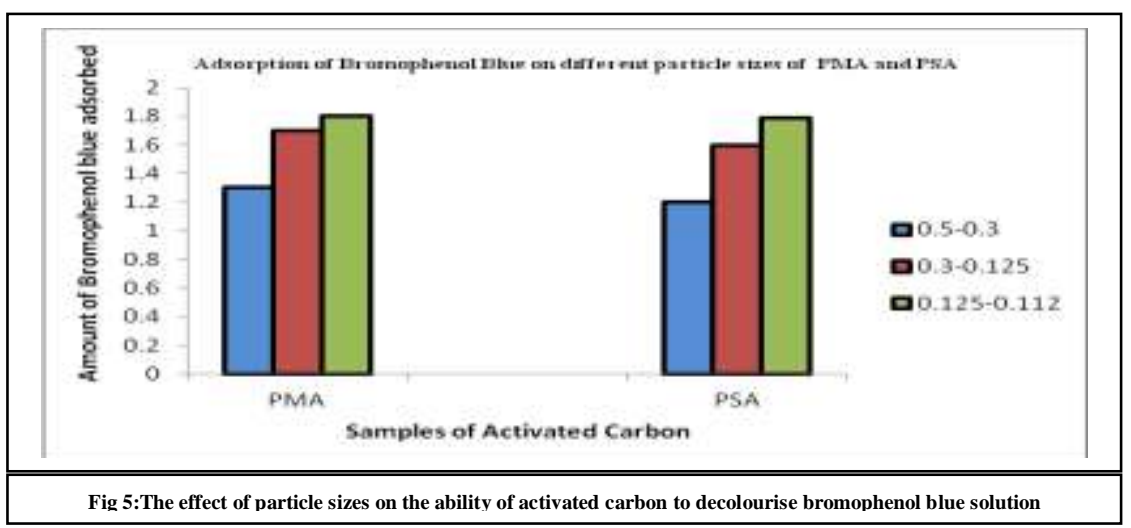

\subsection{ADSORPTION OF BROMOPHENOL BLUE SOLUTION ONTO SAMPLES OF ACTIVATED CARBON}

The result of adsorption characteristics of activated carbon are shown in the table 3 . Due to the adsorption ability of each activated carbon samples, decolourisation was effected in all the coloured solution prepared at different concentrations. The concentrations used for this analysis are $20 \mathrm{mg} / \mathrm{l}$ and $30 \mathrm{mg} / \mathrm{l}$ for Bromophenol blue and Methyl orange solution respectively. Samples of activated carbon with particle size $(0.125-0.112) \mu \mathrm{m}$ was chosen for this adsorption study. The results are interpreted in form of bar charts in the figure 6 and 7 below:

Table 3: Adsorption of bromophenol blue solution onto samples of activated carbon

\begin{tabular}{|c|c|c|c|}
\hline $\begin{array}{c}\text { Samples of activated } \\
\text { carbon }\end{array}$ & $\begin{array}{c}\text { Adsorbance of decolourized } \\
\text { solution }( \pm 0.001)\end{array}$ & $\begin{array}{c}\text { Concentration of } \\
\text { decolourized } \\
\text { Solution }( \pm 0.01 \mathrm{mg} / \mathrm{l})\end{array}$ & $\begin{array}{c}\text { Quantity of solute adsorbed }( \\
\pm 0.1 \mathrm{mg})\end{array}$ \\
\hline PMA & 0.150 & 1.0875 & 1.89 \\
ZMA & 0.220 & 4.0375 & 1.59 \\
KMA & 0.298 & 5.0375 & 1.49 \\
PSA & 0.154 & 2.0625 & 1.79 \\
ZSA & 1.090 & 19.0625 & 0.084 \\
KSA & 1.015 & 18.0125 & 0.20 \\
CAC & 0.085 & 1.0333 & 1.90 \\
\hline
\end{tabular}

The calculation of quantity of solute adsorbed is thus:

$$
Q=\frac{V\left(C_{i}-C_{f}\right) m g / \mathrm{cm}^{3}}{1000} \text { [12] }
$$

$\mathrm{C}_{\mathrm{i}}$ is the initial concentration before the adsorption and $\mathrm{C}_{\mathrm{f}}$ is the final concentration after adsorption e.g for PMA of $(0.125-0.112) \mu \mathrm{m}$ particles size ranges. $\mathrm{C}_{\mathrm{i}}=20 \mathrm{mg} / \mathrm{l}$ for bromophenol blue $\mathrm{C}_{\mathrm{f}}=1.0875 \mathrm{mg} / \mathrm{l}$ determined from the graph $\mathrm{V}=100 \mathrm{~cm}^{3}$ (Volume of the solution prepared from the stock solution).

$$
\therefore Q=\frac{100(20-1.0875) \mathrm{mg} / \mathrm{cm}^{3}}{1000}=1.89 \mathrm{mg}
$$

This calculation is repeated for all the remaining quantities of solute adsorbed. 
Comparative Adsorption Of Dyes Unto Activated Carbon Prepared From Maize Stems And Sugar

From table 5 and figure 6 it was observed that maize stem activated with orthophosphoric acid almost showed the same quantity of solute adsorbed with commercial activated carbon, CAC. The decreasing order of adsorption of solute are:

i. $\quad$ PMA $>$ ZMA $>$ KMA

ii. $\mathrm{PSA}>\mathrm{KSA}>\mathrm{ZSA}$

Samples with the same activating reagents follow the trend:

i. $\mathrm{KMA}>\mathrm{KSA}$

ii. ZMA >ZSA while PMA and PSA relatively had the same adsorptive capacity.

Samples of activated carbon produced with orthophosphoric acid as the activating reagent was observed to have the highest adsorption capacity in Bromophenol blue and this shows that orthophosphoric is the best activating agent suitable for Bromophenol blue decolourisation.

\subsection{DECOLOURIZATION CHARACTERISTIC IN METHYL ORANGE SOLUTION}

The results of adsorption ability of the activated carbon samples in methyl orange are given in table 4 and it was interpreted as bar charts in figure 7. The concentration of methyl orange solution used is $30 \mathrm{mg} / \mathrm{L}$

Table 4: Adsorption of Methyl Orange Solution onto samples of activated carbon

\begin{tabular}{|c|c|c|c|}
\hline $\begin{array}{c}\text { Samples of activated carbon } \\
\text { analyzed }\end{array}$ & $\begin{array}{c}\text { Adsorbance of } \\
\text { Decolourized } \\
\text { Solution }( \pm 0.001)\end{array}$ & $\begin{array}{c}\text { Concentration of } \\
\text { Decolourized Solution } \\
( \pm 0.01 \mathrm{mg} / \mathrm{L})\end{array}$ & $\begin{array}{c}\text { Quantity of Solute } \\
\text { Adsorbed } \\
( \pm 0.1 \mathrm{mg})\end{array}$ \\
\hline PMA & 0.094 & 3.25 & 2.67 \\
ZMA & 0.201 & 6.45 & 2.35 \\
KMA & 0.700 & 24.125 & 0.59 \\
\hline PSA & 0.106 & 3.375 & 2.66 \\
ZSA & 0.118 & 4.125 & 2.58 \\
KSA & 0.141 & 5.00 & 2.5 \\
CAC & 0.080 & 2.375 & 2.76 \\
\hline
\end{tabular}

The quantities of solute adsorbed in methylorange is calculated using the same approach used in the adsorption of bromophenol blue.
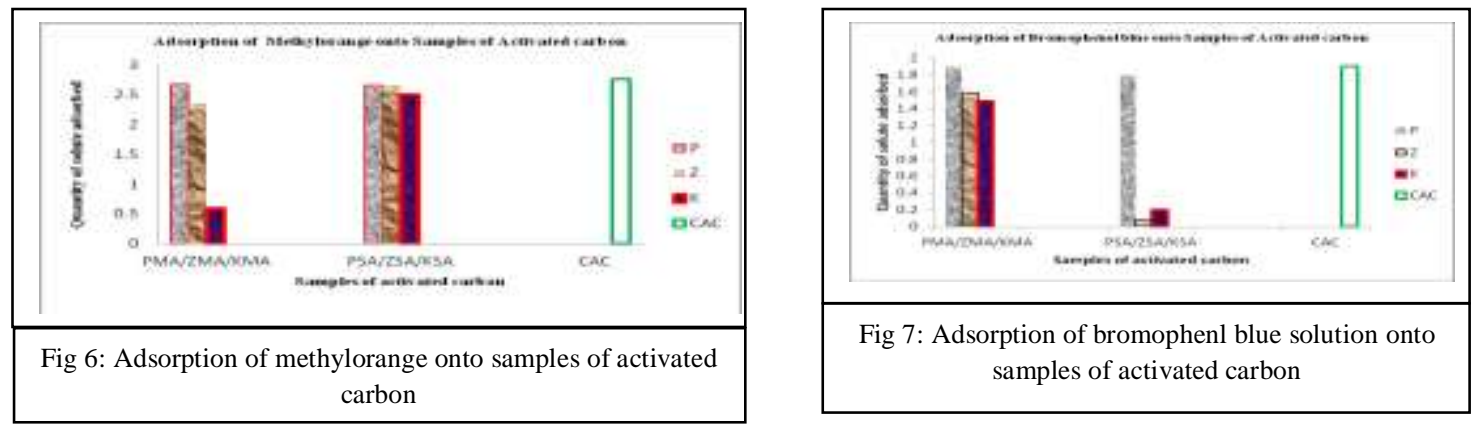

From the data in table 6 and figure 7, the decolourization characteristics of different activated carbon samples was shown by the adsorption of the methyl orange solution. The trend is as follows:

\section{i. $\mathrm{PMA}>\mathrm{ZMA}>\mathrm{KMA}$ \\ ii.PSA $>$ ZSA $>$ KSA}

In the above trend, PMA and PSA had the highest adsorption capacity among the activated carbon prepared from the same raw agricultural waste. However, this compared favourably with commercial activated charcoal (CAC).

\subsection{DETERMINATION OF ASH CONTENT AND PERCENTAGE FIXED CARBON}

The results of ash content analysis is presented in tables 5 and 6 and these tables portrayed the values of percentage ash and the percentage fixed carbon for the samples of activated carbon.

\begin{tabular}{|c|c|c|c|c|}
\hline Sample & $\begin{array}{l}\text { Weight of } \\
\text { crucibles } \\
\text { (g) }\end{array}$ & $\begin{array}{l}\text { Weight of ash } \\
+ \text { crucible }(\mathrm{g})\end{array}$ & $\begin{array}{c}\text { Weight of } \\
\text { ash }(\mathrm{g})\end{array}$ & $\begin{array}{c}\text { Percentage ash } \\
(\%)\end{array}$ \\
\hline PMA & 56.00 & 56.37 & 0.1512 & 15.12 \\
\hline KMA & 20.73 & 21.11 & 0.152 & 15.2 \\
\hline ZMA & 56.0 & 56.385 & 0.154 & 15.4 \\
\hline PSA & 20.73 & 21.11 & 0.15 & 15.2 \\
\hline KSA & 10.74 & 11.14 & 0.16 & 16.0 \\
\hline ZSA & 15.8 & 16.22 & 0.168 & 16.8 \\
\hline
\end{tabular}




Table 6: Percentage ash and percentage fixed carbon of samples of activated carbon
\begin{tabular}{|l|l|l|}
\hline Sample & Percentage ash $(\%)$ & Percentage fixed carbon \% \\
\hline PMA & 15.12 & 84.88 \\
KMA & 15.2 & 84.80 \\
ZMA & 15.4 & 84.60 \\
\hline PSA & 15.2 & 84.80 \\
KSA & 16.0 & 84.0 \\
ZSA & 16.8 & 83.20 \\
\hline
\end{tabular}

The increasing order of the percentage fixed carbon of the adsorbent above is:

$\mathrm{PMA}>(\mathrm{PSA} \approx \mathrm{KMA})>\mathrm{ZMA}>\mathrm{KSA}>\mathrm{ZSA}$. It was observed that samples with the lowest percentage fixed carbon have the lowest adsorption capacity and this finding agreed with that of Okeola, 1999 [13]. Samples of activated carbon from maize cobs and sugarcane stem showed almost the same and a very close value to each other.

\section{Conclusion}

The activated carbon prepared from maize stem activated with orthophosphoric acid (PMA) showed the greatest adsorption capacity and its adsorption capacity is comparable with that of commercial activated carbon (CAC). In the adsorption of bromophenol blue solution, PMA showed a distinct characteristic while in the adsorption of methyl orange, both PMA and PSA had relatively the same quantity of solute adsorbed. The results of this study show that the magnitude of adsorption capacity of activated carbon can be influenced by various factors such as: The nature of raw material from which the activated carbon is prepared, the activating reagents used and the nature of the solute material being adsorbed (i.e. the adsorbate like bromophenol blue solution). The percentage ash and the percentage fixed carbon were estimated and activated carbon produced form maize cobs, PMA was observed to have the highest percentage fixed carbon. In this research, it can be concluded that PMA and PSA were the best for the adsorption of the dyes (bromophenol blue and methyl orange) because they both possess the highest and unbeatable adsorption capacity and this compete favourably with CAC. From the outcome of this research, it can be concluded that activated carbon prepared from low cost agricultural waste can conveniently replace the commercial ones.

\section{Acknowledgment}

We use this medium to appreciate the management of Landmark University for the land breaking input in the supply of research equipments into the department of Industrial Chemistry for core teaching and research activities.

\section{References}

[1] R.O. Milind., D. Julie, and J. Snehal. "Comparative adsorption studies on Activated Rice Husk and Rice Husk Ash by using Methylene Blue as dye," International Congress on Environmental Research at Bits Pilani ,2009, GOA, 1 - 11

[2] S. E. Agarry and B. O. Solomon. "Kinetics of batch microbial degradation of phenols by indigenous Pseudomonas fluorescence". Int. J. Environ. Sci. Tech., 5(2), 2008, 223-232.

[3] B. Subramanyam and A. Das . "Linearized and non-linearized isotherm models comparative study on adsorption of aqueous phenol solution in soil "'. Int. J. Environ. Sci. Tech., 6 (4), 2009, 633-640

[4] J. C. Igwe and A.A. Abia. "A bioseparation process for removing heavy metals from waste water using biosorbents". African Journal of Biotechnology . 5(12), 2006, 167-1179

[5] N.T. Abdel-Ghani; Hefny, M. and G.A.F. El-Chagbaby. "Removal of Lead (II) from aqueous solution using low cost abundantly available adsorbents". Int. J. Environ. Sci. Tech., 4 (1), 2007, 67-73 .

[6] G.O. Adediran., F.O. Nwosu., and F.A. Adekola. "Some Langmuir adsorption parameters of activated carbon produced from local materials" Nig. J. Pure \& Appl. Sci. 15(1), 2000, $1075-1082$

[7] H.I. Adekoge and F.A. Adekola. Adsorption of Lead (II) ion from aqueous solution of activated carbon from coconut coirpith" $J$. Chem. Soc. Nigeria, 36(2), 2011, 134-138

[8] E.O. Odebunmi and O.F. Okeola. "Preparation and characterization of activated carbon from Waste Material", J. Chem. Soc. Nigeria 26 (2), 2001, 149- 155.

[9] H. David, N.K. Jai, and L, Clint (1993). Aldrich: Catalog Handbook of Fine Chemicals, Alderich Chemical Company, Inc., 1993, 3343-3344, 5430-5431

[10] O. Ogbonaya. "Preparation and Comparative Characterisation of Activated Carbon from Nigeria sub-bituminous coal, palm kernel and Cowbone", J. Chem. Soc. Nig. $\underline{\text { 21}}, 1992,11-14$

[11] D.G. Duff and S.M. Ross."Adsorption on Activated Charcoal, J. of Chem. Educ., 65(3), 1968, 815-816

[12] M. Vanderborght and E. Van Grieken (1977). Enrichment of trace metals in water by adsorption on activated carbon. Anal. Chem 49(2), 1977, $311-316$.

[13] O.F. Okeola. "preparation and characterization of activated carbon from various waste matereials" M.Sc Thesis, University of Ilorin, Nigeria; pp 5, 18-37, 1999.

[14] G.H. Sheffler . "Carbon Activated" Encyclopedia of Industrial Xhemical Analysis. Vol 8, $1^{\text {st }}$ Edition, Interscience Publisher, New York. pp $139-16,1969$. 